\title{
Self assembly of $C$-methyl resorcin[4]arene with coumarin and thiocoumarin: A nanotubular array with a near perfect lock and key fit
}

\author{
LEPAKSHAIAH MAHALAKSHMI, PARTHA P DAS and TAYUR N GURU ROW* \\ Solid State and Structural Chemistry Unit, Indian Institute of Science, Bangalore 560012 \\ e-mail: ssctng@sscu.iisc.ernet.in
}

\begin{abstract}
The host-guest complex of $C$-methyl resorcin[4]arene with coumarin and thiocoumarin has been characterized by single crystal X-ray diffraction technique. Structural analysis shows that the host forms an infinitie nanotubular array in which the guest coumarin shows a 'head to tail' arrangement of dimers held together by $\pi \ldots \pi$ interaction in the host framework. Similar structural motif is observed when thiocoumarin used as a guest.
\end{abstract}

Keywords. Host-guest inclusion; self-assembly; resorcinarene; coumarin; nanotubular array.

\section{Introduction}

Design, synthesis and characterization of nano-sized tubular architecture on one hand and its possible applications in chemistry, biology and materials science on the other are of current research interest. ${ }^{1}$ Weak interactions and geometrical constraints of building blocks together engineer supramolecular assemblies and therefore make a priori predictions of the resulting superstructures difficult. ${ }^{2}$ The discovery of single-walled carbon nanotubes and their importance in areas like superconductivity and molecular electronics ${ }^{3}$ have triggered significant research in the generation of other multi-component organic nano-materials. Such molecules allow for the encapsulation of suitable guest molecules and thus open up possibilities of futuristic materials design with specific applications. ${ }^{1}$ Organic tubular nano structures have been constructed in recent times making use of radial disk shaped or non-disk shaped building blocks. ${ }^{1 \mathrm{c}, 4}$ While cyclo peptides form disk shaped stable nano tubes, calixarenes and related compounds form the precursors for non-disk shaped nano capsules. ${ }^{5,6}$ In this article, we report the design and control of a nanotube with optimized perfect fit to hold the guest molecule, coumarin, in a templated environment provided by $C$-methyl resorcin[4]arene.

\footnotetext{
*For correspondence
}

\section{Experimental}

\subsection{Synthesis}

The host $C$-methylcalix[4]resorcinarene(CMCR) [1] was synthesized by improving on the solid state method reported by Raston et $a l^{7}$ and adopting a more economical route as reported here.

\section{1a Synthesis of host; C-methylcalix[4]resor-} cinarene(CMCR) [1]: Resorcinol $(567 \mathrm{mg}$, $5.15 \mathrm{mmol}$ ) and the catalyst $p$-toluene sulfonic acid (50 mg, $0.02 \mathrm{mmol}$ ) were ground in a mortar and pestle. To the above mixture $35 \%$ acetaldehyde solution $(0.63 \mathrm{ml}, 5.15 \mathrm{mmol})$ was added drop-wise with stirring, when a paste was formed after 5$10 \mathrm{~min}$. This in turn solidified on standing for two hours. The solid was then washed with water and filtered and dried. Yield: $540 \mathrm{mg}$, m.p. $>360^{\circ},{ }^{1} \mathrm{H}$ NMR $\left(400 \mathrm{MHz}, \quad \mathrm{CD}_{3} \mathrm{CN}, \quad 300 \mathrm{~K}\right): \quad d=1.70 \quad(d$, $\left.3 \mathrm{~J}=7.3 \mathrm{~Hz}, 12 \mathrm{H} \mathrm{CH} \mathrm{CH}_{3}\right), 4.44(q, 3 \mathrm{~J}=7.4 \mathrm{~Hz}, 4 \mathrm{H}$, $\mathrm{CH}), 6.20(s, 4 \mathrm{H}, \mathrm{Ar}$ ortho $\mathrm{OH}), 7.34(s, 4 \mathrm{H}, \mathrm{Ar}$ meta $\mathrm{OH}), 8.03(b r, 8 \mathrm{H}, \mathrm{OH}) .{ }^{13} \mathrm{C}$ NMR $(100 \mathrm{MHz}$, $\left.\mathrm{CD}_{3} \mathrm{CN}, 300 \mathrm{~K}\right): d=20 \cdot 8,29 \cdot 4,104 \cdot 6,125 \cdot 8,127 \cdot 0$, $153 \cdot 0$.

2.1b Synthesis of host-coumarin-acetone complex [2]: $54.4 \mathrm{mg}(0.1 \mathrm{mmol})$ of host and $7.31 \mathrm{mg}$ $(0.05 \mathrm{mmol})$ of coumarin were ground and $4 \mathrm{ml}$ of acetone was added. Slow evaporation of solution at R.T. yielded X-ray quality crystals after 2 weeks. 
Table 1. Crystal data and structure refinement details for compounds 2 and 3.

\begin{tabular}{|c|c|c|}
\hline & 2 & 3 \\
\hline Empirical formula & $\mathrm{C} 106 \mathrm{H} 100 \mathrm{O} 26$ & C108 H88 O26 S4 \\
\hline Formula weight & $1789 \cdot 86$ & $1930 \cdot 02$ \\
\hline Temperature (K) & $293(2)$ & $293(2)$ \\
\hline Wavelength $(\AA)$ & 0.71073 & 0.71073 \\
\hline Crystal system & Monoclinic & Monoclinic \\
\hline Space group & $C 2 / c$ & $C 2 / c$ \\
\hline \multicolumn{3}{|l|}{ Unit cell dimensions } \\
\hline$a(\AA)$ & $15 \cdot 52(2)$ & $15 \cdot 63(2)$ \\
\hline$b(\AA)$ & $14 \cdot 48(2)$ & $14 \cdot 62(2)$ \\
\hline$c(\AA)$ & $21 \cdot 08(3)$ & $20 \cdot 88(3)$ \\
\hline$\alpha, \beta, \gamma(\mathrm{deg})$ & $90,109 \cdot 38(2), 90$ & $90,109 \cdot 85(2), 90$ \\
\hline Volume $\left(\AA^{3}\right)$ & $4470 \cdot 0(10)$ & $4490(10)$ \\
\hline Crystal size (mm) & $0.25 \times 0.18 \times 0.15$ & $0.23 \times 0.15 \times 0.12$ \\
\hline Z & 4 & 4 \\
\hline Calculated density $\left(\mathrm{mg} / \mathrm{m}^{3}\right)$ & $1 \cdot 330$ & $1 \cdot 357$ \\
\hline Absorption coefficient $\left(\mathrm{mm}^{-1}\right)$ & 0.095 & $0 \cdot 186$ \\
\hline$F(000)$ & 1888 & 1920 \\
\hline$\theta_{\min , \max }$ & 1.98 to 28.02 & 1.96 to 25.00 \\
\hline$h_{\min , \max }$ & $-20,20$ & 18,18 \\
\hline$k_{\min , \max }$ & $-18,19$ & $-17,17$ \\
\hline$l_{\min , \max }$ & $-27,27$ & $-24,24$ \\
\hline Reflections collected/unique & $19129 / 5271[R(\mathrm{int})=0.0623]$ & $20447 / 3961[R(\mathrm{int})=0.0943]$ \\
\hline Completeness to & $\theta=28 \cdot 02,97 \cdot 6 \%$ & $\theta=25 \cdot 00,100 \cdot 0 \%$ \\
\hline Refinement method & Full-matrix least-squares on $F^{2}$ & Full-matrix least-squares on $F^{2}$ \\
\hline Data/restraints/parameters & $5271 / 0 / 306$ & $3961 / 0 / 300$ \\
\hline Goodness-of-fit on $F^{2}$ & 1.004 & 1.499 \\
\hline Final $R$ indices $[I>2 \sigma(I)]$ & $R 1=0.0606, w R 2=0.1251$ & $R 1=0.1392, w R 2=0.3628$ \\
\hline $\mathrm{R}$ indices (all data) & $R 1=0.1228, w R 2=0.1514$ & $R 1=0.1591, w R 2=0.4114$ \\
\hline$\Delta \rho_{\max }, \Delta \rho_{\min }\left(\mathrm{e} . \AA^{-3}\right)$ & 0.305 and -0.265 & -1.085 and 1.362 \\
\hline
\end{tabular}

2.1c Synthesis of host-thiocoumarin complex [3]: $27.2 \mathrm{mg}(0.05 \mathrm{mmol})$ of host and $16 \mathrm{mg}(0.1 \mathrm{mmol})$ of 1-thiocoumarin were ground together and then dissolved in acetonitrile. X-ray quality crystals were obtained by redissolving the thin crystals in acetonitrile by slight warming and then adding a few drops of diethyl ether.

\subsection{Crystallographic details}

The single crystal diffraction data were collected on a Bruker AXS Smart Apex CCD diffractometer ${ }^{8}$ at 298(2) K. The X-ray generator was operated at $50 \mathrm{kV}$ and $35 \mathrm{~mA}$ using $\mathrm{MoK} \alpha$ radiation. Data was collected with $\omega$ scan width of $0.3^{\circ}$. A total of 606 frames were collected in three different settings of $\varphi$ $\left(0^{\circ}, 90^{\circ}, 180^{\circ}\right)$ keeping the sample to detector distance fixed at $6.03 \mathrm{~cm}$ and the detector position $(2 \theta)$ fixed at $-25^{\circ}$. All the data were corrected for Lorentzian, polarisation and absorption effects ${ }^{8,9}$. SHELXL- $97^{10}$ was used for structure solution and full matrix least squares refinement on $F^{2}$. Hydrogen atoms were included in the refinement as per the riding model. CCDC-634036 and CCDC-635907 contains the supplementary crystallographic data for this paper. These data can be obtained free of charge via www.ccdc.cam.ac.uk/conts/retrieving.html (or from the Cambridge Crystallographic Data Centre, 12 Union Road, Cambridge CB2 1EZ, UK; fax: $(+44)$ 1223-336-033; or charge via www.ccdc.cam.ac.uk/ conts/retrieving.html (or from the Cambridge Crystallographic Data Centre, 12 Union Road, Cambridge CB2 1EZ, UK; fax: (+44) 1223-336-033; or (deposit@.ccdc.cam.ac.uk).

\section{Results and discussion}

\subsection{Synthesis}

The host $C$-methyl resorcin[4]arene [1] was synthesized at room temperature by a minor modification of the reported solid state method. ${ }^{7}$ Stoichiometric 
variants of 1 and the guest molecule (coumarin for $\mathbf{2}$ and thiocoumarin for 3) were taken in different solvents like acetone, acetonitrile and methanol (scheme 1). Most of the resulting crystals were found to be solvatomorphs of only the host based on the results from structure determination by X-ray diffraction. ${ }^{11}$ Only the 2:1 mixture of host and guest ground in a pestle and mortar and dissolved in acetone gave crystals of the complex-2. The crystal structure was solved by direct methods and refined to a final $R$ value of 0.0623 . The solvent acetone was uniquely identified and all hydrogen atoms were fixed at their calculated positions based on stereochemistry during the refinements. In order to check the specificity of the coumarin incorporation in the guest-host complexation, 1-thiocoumarin has been used as a guest

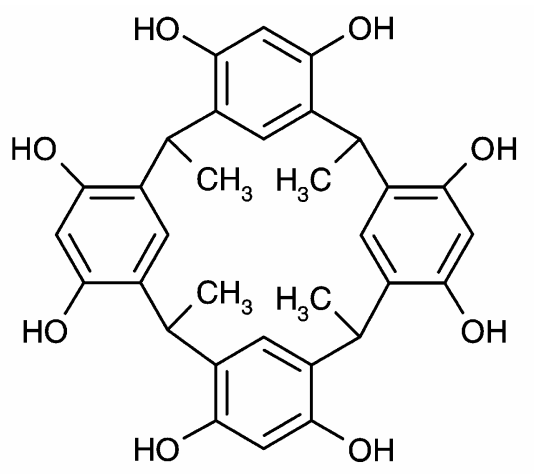<smiles>[X]c1ccc2ccccc2c1</smiles>

$\mathrm{X}=\mathrm{O}, \mathrm{S}$

molecule instead of coumarin and the crystallization was carried out in the presence of acetonitrile. The crystals have nearly the same cell parameters with the space group $C 2 / c$. Powder diffraction data confirmed that the bulk material has the same composi-

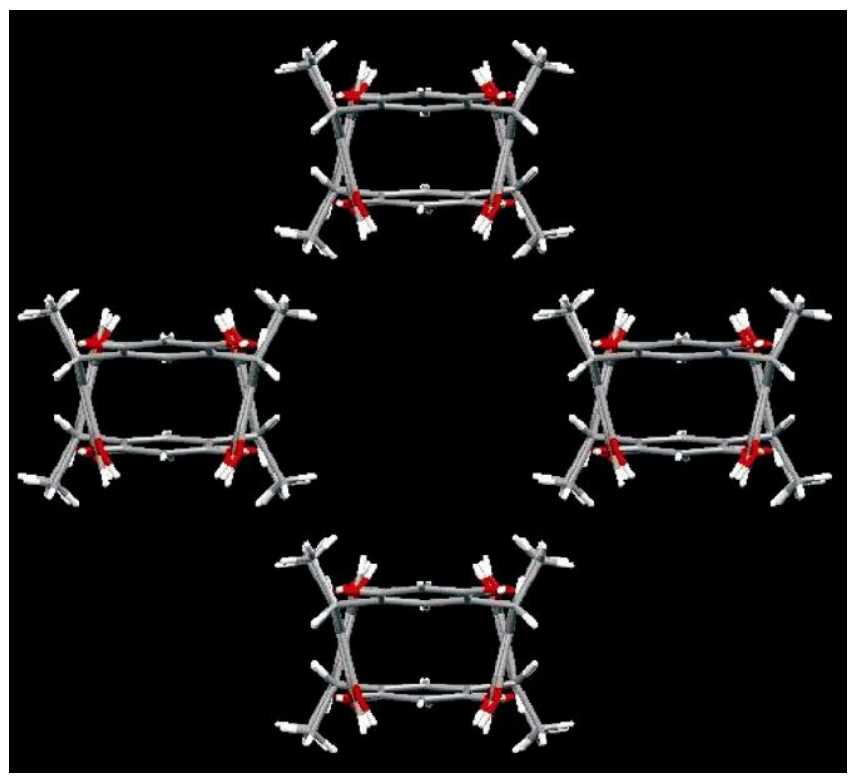

Figure 2. Tetrameric assembly of host formed by infinite chains of host molecule. Guest and solvent molecules are removed for clarity.

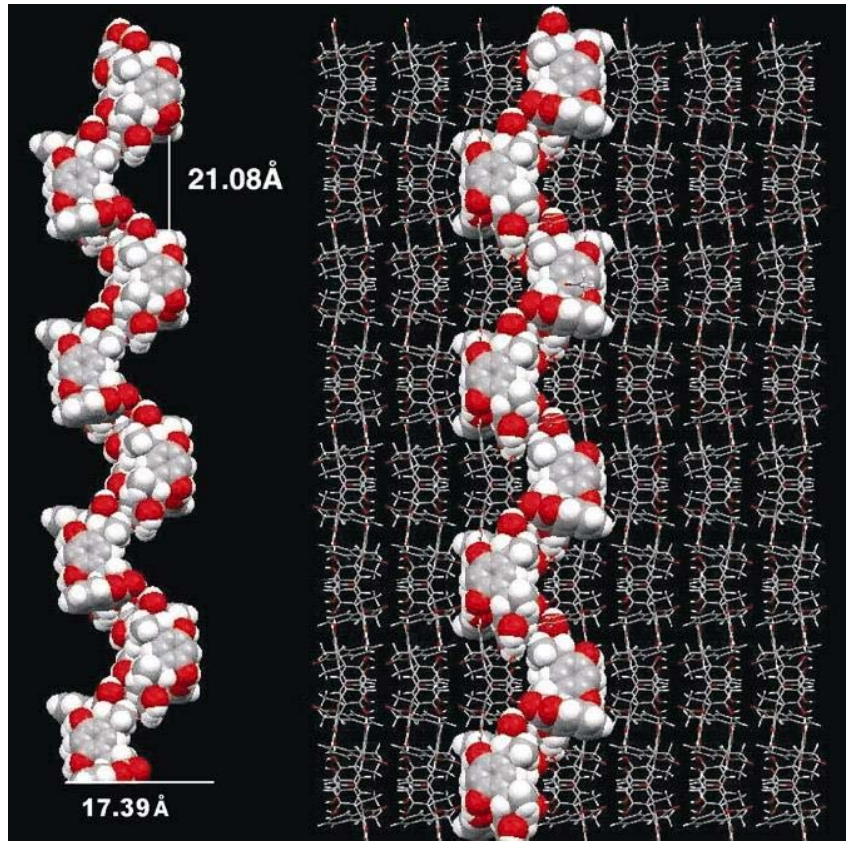

Figure 3. Zig-Zag motif of resorcinarene in 2 shown with van der Waal radii, the width of the cavity is $17.39 \AA$ and the pitch of the single helix is $21.08 \AA$ respectively.

Figure 1. ORTEP diagram of the complex 2 showing all the three participating molecular species.
Scheme 1. Molecular structure of $C$-methylresorcin[4] arene(host) 1 and coumarin/thiocoumarin (guest).

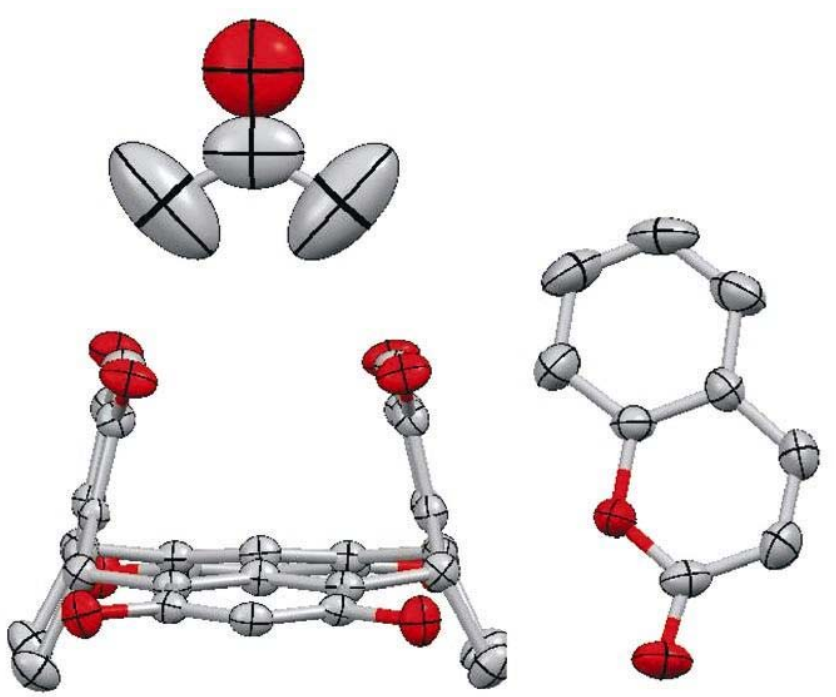


tion as determined by single crystal analysis (see supplementary material).

\subsection{Details of crystal structure analysis}

The host-guest complex of CMCR with coumarin and 1-thiocoumarin (2 and 3) are isomorphous and

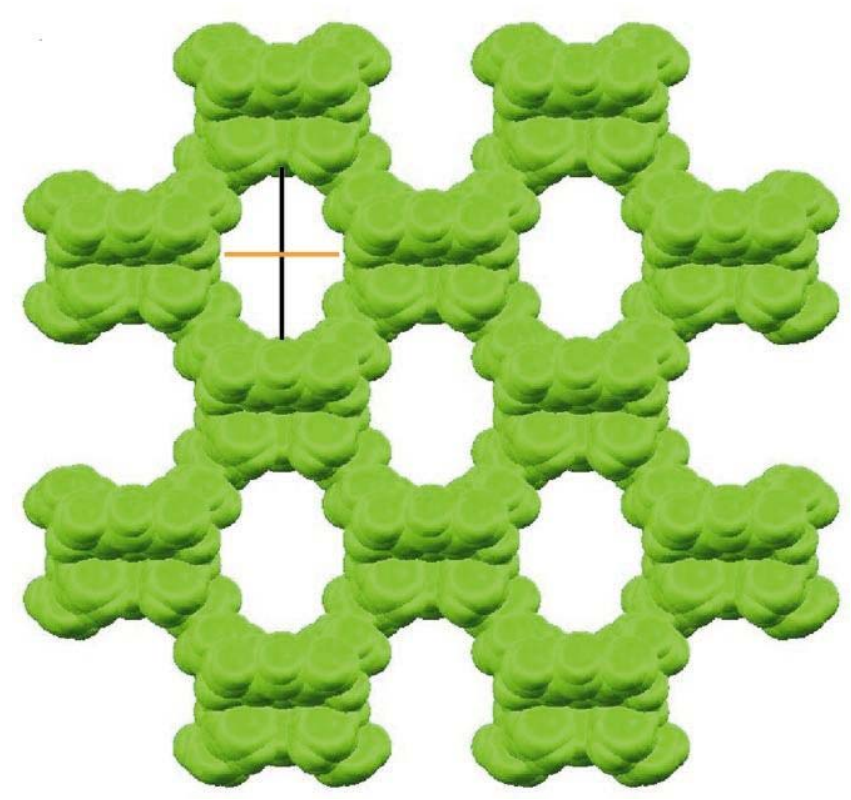

Figure 4. Space filling view of the empty channel showing the elliptical shape and dimension (vertical axis black $15.7 \AA$ and horizontal axis orange $11.3 \AA$ ).

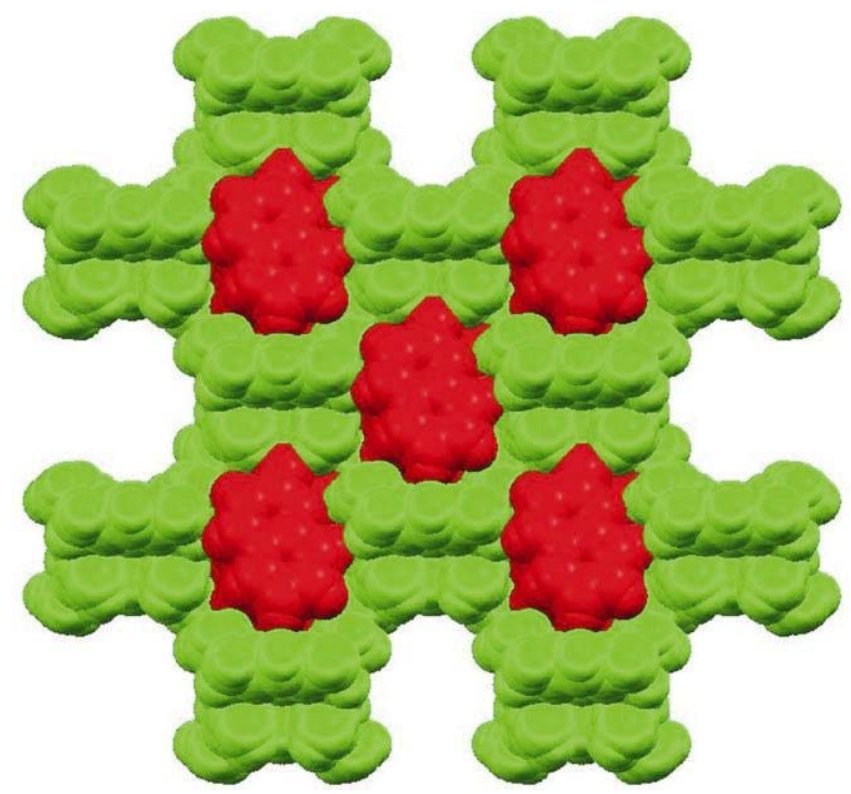

Figure 5. Space filling view of the nanotubular channel filled with the guest molecules as well as sandwiched solvent acetone molecules. Colour code: Host in green and coumarin in red. crystallize in monoclinic system in the space group $C 2 / c$ (table 1). The structure of complex 2 is discussed in detail. The asymmetric unit in 2 consists of one coumarin molecule (guest), half resorcinarene (host) along with a half molecule of acetone (solvent). The other half of the host and that of the solvent is generated by the crystallographic $c$-glide. The host thus takes up a 'boat' conformation (figure 1) instead of more stable 'crown' conformation which is commonly observed in host-guest complexes of $C$-methylresorcin[4]arene. It is of interest to note that only $27 \%(28 / 103)$ hits based on CSD analysis for 1 display the 'boat' conformation while a larger number (63\%) display the more stable 'crown' conformation for 1 . The flattened cone conformation of 1 is a consequence of the formation of strong intermolecular $\mathrm{O}-\mathrm{H} \ldots \mathrm{O}$ bonds $[\mathrm{O} \ldots \mathrm{O}$ separations: $2 \cdot 76-2.87 \AA]$ between neighbouring hosts as well as the carbonyl oxygen of the guest molecule $[\mathrm{C}=\mathrm{O} \ldots \mathrm{O} 2.76-2.81 \AA]$. Further stabilization is provided by well-defined weak but directional $\mathrm{C}$ $\mathrm{H} \ldots \pi$ between guest and host $[\mathrm{C}-\mathrm{H}$ (guest) $\ldots \pi$ (host) $2.685 \AA]$ along with the well-characterized $\pi-\pi$ stacks in the host assembly. ${ }^{12}$

It has been demonstrated that the size of cavity in the framework generated by $\mathbf{1}$ can be adjusted to the guest molecule through different backbone formation or alterations in the support spacer molecule. ${ }^{13}$ The supramolecular assembly of the host in complex 2 forms a well-defined nanotubular structure built by a network of weak interactions $[\pi$ (host) $\ldots \pi$ (host) $3.82 \AA, \mathrm{C}-\mathrm{H}$ (host)... O(host) $2.52-2.66 \AA]$. The asymmetric unit of the nanotube has eight host, four coumarin and two acetone molecules (figure 2). The host molecules by themselves form a tetrameric unit of dimers which provides a cavity of dimension $15.7 \AA / 11.3 \AA$ when viewed down $z$-axis. The assembly of host, guest and solvent molecules thus generate a helical motif in the crystal packing when viewed down $x$-axis (figure 3 ). The features of the nanotube as viewed down the channel depict the overall shape of the elliptical cavity generated by 1 as shown in figure 4 . The incorporation of the guest molecules along with the sandwiched acetone molecules in the cavity results in a near perfect lock and key fit as seen in figure 5 . The cavity created by the assembly of the host molecules accommodates two coumarin molecules at a distance of $3.909 \AA$ via $\pi \ldots \pi$ stacking interactions in a 'head to tail' manner across a center of symmetry. Acetone molecules are sandwiched between adjacent pairs of coumarin molecule as shown in figure 6 . Weak $\mathrm{C}-\mathrm{H} \ldots \pi$ 

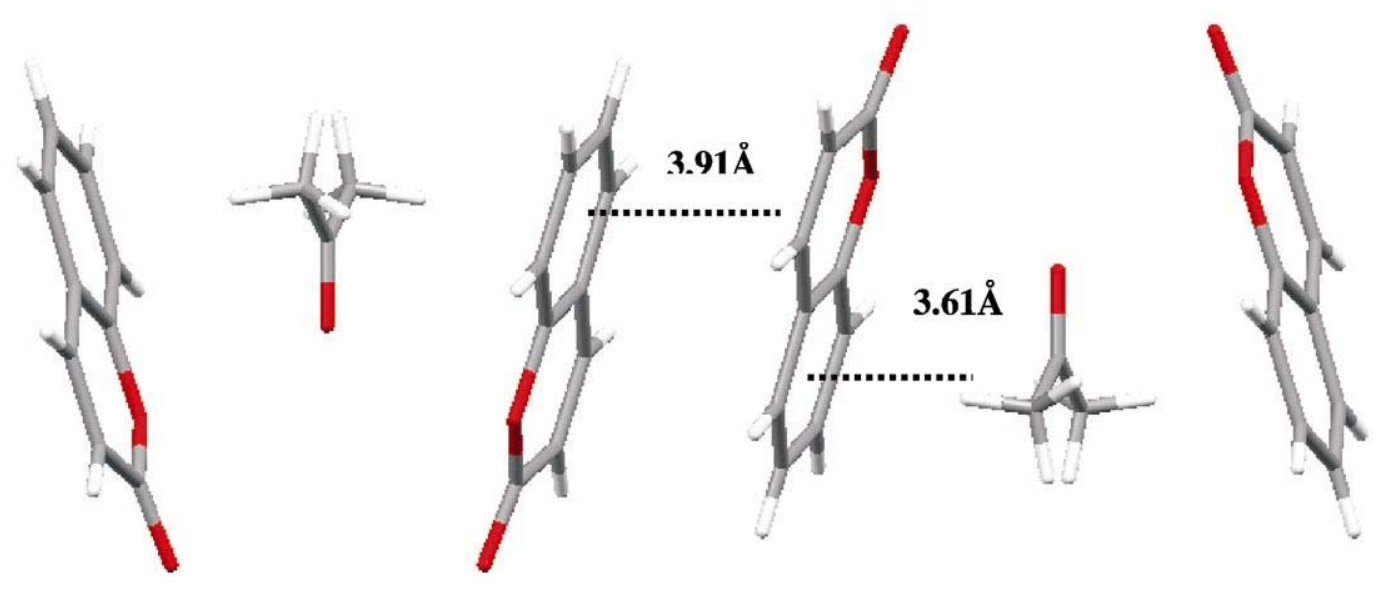

Figure 6. The supramolecular assembly of the coumarin and sandwiched solvent in the unit cell of 2 .

(3.64-3.95 A) interactions between guest and solvent hold the sandwich in place and help in keeping the coumarin pairs at a distance suitable for photodimerization $^{14}$ (stacking distance $=3.909 \AA<4.2 \AA$ as specified). In the host-guest complex 3 thiocoumarin molecules are arranged in a similar 'head to tail' manner with the $\pi \ldots \pi$ stacking distance of $3.974 \AA$. It is noteworthy that the sandwich here has a certain amount of electron density smeared over a large region making it difficult to assign any solvent system.

\section{Conclusions}

In conclusion, it has been demonstrated that with the 'boat' conformation of the $C$-methyl resorcin[4] arene (host), nano tubes have been generated in the crystal structure with coumarin and thiocoumarin molecules (guest) sandwiching acetone (solvent) in the former and a disordered solvent in the latter respectively in the complex resulting in a near lock and key fit. The realization of the arrangement of the guest molecules in a cavity with stacking distances suitable for photodimerization opens up new vistas in solid-state photoreaction studies in such complexes.

Supplementary Material: ORTEP and packing diagram for $\mathbf{2}$ and 3; Calculated and experimental PXRD of 2 (figures Al-A6).

\section{Acknowledgements}

We thank the Department of Science and Technology (DST), India for financial support and DST-IRHPA for CCD facility in Indian Institute of Science.

\section{References}

1. (a) Dalgarno S J, Tucker S A, Bassil D B and Atwood J L 2005 Science 309 2037; (b) Heinz T, Rudkevich D M. and Rebek Jr J 1998 Nature (London) 394 764; (c) Dalgarno S J, Cave G W V and Atwood J L 2006 Angew. Chem. Int. Ed. 45 570; (d) Shivanyuk A and Rebek Jr J. 2001 Chem. Commun. 2374; (e) Murayama K and Aloki K 1998 Chem. Commun. 607; (f) Ugono O. and Holman K T 2006 Chem. Commun. 2144; (g) Mansikkamä H, Nissinen M and Rissanen K 2005 CrystEngComm. 7 519; (h) Ma B Q and Coppens P 2004 Chem. Commun. 932; (i) Perret F, Lazar A N, Shkurenko O, Suwinska K, Dupont N and Navaza A 2006 CrystEngComm. 8890

2. (a) Desiraju G R 2001 Nature (London) 412 397; (b) Steiner T 2002 Angew. Chem. Int. Ed. 41 48; (c) Meyer E A, Castellano R K and Diederich F 2003 Angew. Chem. Int. Ed. 42 1210; (d) Ma J C and Dougherty D A 1997 Chem. Rev. 971303

3. Dresselhaus M S, Dresselhaus G P and Eklund P C 1995 Science of fullerenes and carbon nanotubes: Their properties and applications (San Diego: Academic Press)

4. Bong D T, Clark T D, Granja J R and Ghadiri M R 2001 Angew. Chem. Int. Ed. $\mathbf{4 0} 988$

5. (a) Ghadiri M R, Granja J R, Milligan R A, McRee D E and Khazanovich N 1993 Nature (London) 366 324; (b) Sánchez-Quesada J, Isler M P and Ghadiri M R 2002 J. Am. Chem. Soc. 124 10004; (c) Gauthier D, Baillargeon P, Drouin M and Dory Y L 2001 Angew. Chem. Int. Ed. 40 4635; (d) Ferdinander-Lopez S, Kim H S, Choi E C, Delgado M, Granja J R, Khasanov A, Kraehenbuehl K, Long G, Weinberger D A, Wilcoxen K M and Ghadiri M R 2001 Nature (London) 412452

6. (a) Hong B H, Bae S C, Lee C-W, Jeong S and Kim K S 2001 Science 294 348; (b) Hong B H, Lee J Y, Lee C-W, Kim J C, Bae S C and Kim K S $2001 J$. Am. Chem. Soc. 12310748 
7. Cave G W V, Hardier M J, Roberts B A and Raston C L 2001 Eur. J. Org. Chem. 173227

8. Bruker 2004 SMART (V 5.628), SAINT (V 6.45a), XPREP, SHELXTL (Wisconsin, USA: Bruker AXS Inc. Madison)

9. Sheldrick G M 1996 SADABS, University of Göttingen, Germany

10. Sheldrick G M 1997 SHELXL97, Program for crystal structure refinement (Germany: University of Göttingen)

11. Mahalakshmi L, Das P P and Guru Row T N Solvatomorphism in CMCR (unpublished)
12. Mansikkamäki H, Nissinen M and Rissanen K 2004 Angew. Chem. Int. Ed. 431243

13. (a) MacGillivray L R and Atwood J L $1997 \mathrm{~J}$. Am. Chem. Soc. 119 6931; (b) Ferguson G, Glidewell C, Lough A J, McManus G D and Meehan P R 1998 J. Mater. Chem. 82339

14. (a) Cohen M D and Schmidt G M J 1964 J. Chem. Soc. 1996; (b) Murthy K V, Guru Row T N and Venkatesan K 2001 Molecular and supramolecular photochemistry (eds) V Ramamurthy and K S Schanze (Marcel Dekker, Inc.) vol. 8, p. 427 